\title{
THE ELECTROCARDIOGRAM IN MITRAL STENOSIS
}

\author{
BY \\ J. R. TROUNCE \\ From the Cardiac Department, Guy's Hospital
}

Received June 22, 1951

For many years certain electrocardiographic changes have been associated with mitral stenosis. As far back as 1913, Sir Thomas Lewis wrote: "The electrocardiograms of mitral stenosis are often so characteristic that the valve lesion may be diagnosed from these curves alone." It has, however, been realized that considerable reservation must be made respecting the value of this investigation in the diagnosis of valvular lesions and it has fallen somewhat into disuse.

The changes most frequently described are increase in the amplitude and duration of the $P$ waves, sometimes associated with alteration in their shape, and a tendency to right axis deviation. More recently the introduction of unipolar limb and præcordial leads has allowed a more accurate assessment of the relative part played by the position of the heart and by the size of the ventricles; while new methods of investigation, including cardiac catheterization, have clarified many of the problems of the normal and abnormal heart.

In this paper the electrocardiographic changes in 75 cases of mitral stenosis are analysed and related to the radiological findings, and in 35 cases to the findings from cardiac catheterization.

Material and Method. The patients are those who have been attending Guy's Hospital with a view to mitral valvulotomy. It is arguable, therefore, that they would belong to the group of patients who fulfil the criteria for this operation (Baker, Brock, and Campbell, 1950); this is probably true to some extent, particularly in those who have been catheterized, for this investigation has usually been done as a prelude to operation.

The diagnosis of mitral stenosis in this series has been made on the finding of the characteristic physical signs and confirmed by fluoroscopy. No case has been included that on clinical and radiological grounds could be diagnosed as predominantly mitral regurgitation. All cases with clinical or radiological evidence of aortic disease were excluded, as it was felt that these would only serve to confuse the picture.

The sex and age distribution are shown in Table I. It will be seen that there is a preponderance of women, with an approximate ratio of $2: 1$, and most cases fall in the young adult age group.

TABLE I

Distribution of Age ANd SeX

\begin{tabular}{l|c|c|c|c|c|c|c}
\hline & $0-9$ & $10-19$ & $20-29$ & $30-39$ & $40-49$ & $50-59$ & Total \\
\hline $\begin{array}{l}\text { Men } \\
\text { Women }\end{array}$ & - & 1 & 6 & 7 & 10 & - & 24 \\
\hline
\end{tabular}

All records were made with a visocardiette direct writing machine, with the patient semirecumbent. The usual standard leads were used together with the unipolar limb leads (VR, VL, and VF), and the unipolar chest leads (V1-6). The machine was standardized before recording so that $1 \mathrm{mv} .=1.0 \mathrm{~cm}$. 


\section{THE ResUlts}

$P$ Waves. The earliest descriptions of the electrocardiogram in mitral stenosis nearly all contain reference to $\mathbf{P}$ waves. Lewis described the $\mathbf{P}$ waves as exaggerated in amplitude and often broad, flattened, or notched. He also made the interesting observation that in cases showing auricular fibrillation the $\mathrm{F}$ waves were large and obvious, and in his experience this type of wave was only seen in mitral stenosis.

A more extensive study was made by White in 1925 . He found that in 58 cases of mitral stenosis with normal rhythm 84 per cent showed abnormalities in the amplitude of PI and PII, his criteria of the upper limits of normal being $P I=1 \mathrm{~mm}$., and PII $=3 \mathrm{~mm}$. He also noted a similar increase in the amplitude of the $P$ waves in pulmonary stenosis.

It was generally held that these enlarged $P$ waves were caused by changes in the atria. In 1938 Berliner and Masters published their observation on 113 cases of mitral stenosis that had come to necropsy, and compared the post-mortem findings with those of the electrocardiogram: they concluded that notching of the $P$ waves was the most constant sign, and that marked increase in the amplitude and duration of the $P$ waves was only found in hearts with hypertrophy of both atria, and therefore generally when tricuspid disease also was present.

A more recent survey by Rasmussen and Nyhus (1948) did not show such consistent $P$ wave changes: in only 13 out of 48 cases was there any abnormality of the $P$ waves. The explanation of this difference is variation of the standards of abnormality, their upper limit of normal being as follows: height of PI, $0.2 \mathrm{mv}$. or more; and of PII, $0.25 \mathrm{mv}$. or more; and duration of P, $0.13 \mathrm{sec}$. or more.

In this series the standards laid down by Ashman and Hull (1941) in adults have been used, the range of amplitude being PI from 0 to $1.1 \mathrm{~mm}$. and PII from 0.3 to $2.5 \mathrm{~mm}$., and the range of duration being PII from 0.06 to $0.11 \mathrm{sec}$. In examining the $P$ waves in lead V1 the table published by Leatham (1950) of the variations in one hundred normal hearts has been used.

TABLE II

Height OF P WAVES

\begin{tabular}{|c|c|c|c|c|c|c|c|c|c|c|c|c|c|c|}
\hline \multirow{3}{*}{$\begin{array}{c}\text { Size of } \\
\text { L. Atruim. }\end{array}$} & \multirow{3}{*}{$\begin{array}{l}\text { Aur. } \\
\text { Fib. }\end{array}$} & \multicolumn{12}{|c|}{ Height of $P$ waves in $\mathrm{mm}$. } & \multirow{3}{*}{$\begin{array}{l}\text { Total } \\
\text { number } \\
\text { of cases }\end{array}$} \\
\hline & & \multicolumn{8}{|c|}{ Positive } & \multicolumn{4}{|c|}{ Negative } & \\
\hline & & 5 & 4 & 3 & $2 \cdot 5$ & 2 & $1 \cdot 5$ & 1 & 0.5 & 0.5 & $1 \cdot 0$ & $1 \cdot 5$ & 2 & \\
\hline $\begin{array}{l}\text { LA, N or + } \\
\text { LA, }++ \\
\text { Total }\end{array}$ & $\begin{array}{c}7 \\
11 \\
23^{*}\end{array}$ & - & - & $\frac{1}{1}$ & $\begin{array}{l}3 \\
1 \\
4\end{array}$ & $\begin{array}{l}3 \\
2 \\
5\end{array}$ & $\begin{array}{r}9 \\
1 \\
10\end{array}$ & $\begin{array}{r}21 \\
4 \\
25\end{array}$ & $\begin{array}{l}6 \\
1 \\
7\end{array}$ & - & - & - & E & $\begin{array}{l}50 \\
20 \\
75^{*}\end{array}$ \\
\hline $\begin{array}{l}\text { LA, } \mathbf{N} \text { or }+ \\
\text { LA, + }+ \\
\text { Total }\end{array}$ & $\begin{array}{c}7 \\
11 \\
23 *\end{array}$ & $\frac{1}{1}$ & $\begin{array}{l}5 \\
1 \\
6\end{array}$ & $\begin{array}{l}2 \\
2 \\
4\end{array}$ & $\frac{8}{8}$ & $\begin{array}{l}7 \\
2 \\
9\end{array}$ & $\frac{11}{11}$ & $\begin{array}{r}8 \\
2 \\
10\end{array}$ & $\begin{array}{l}1 \\
2 \\
3\end{array}$ & - & - & - & - & $\begin{array}{l}50 \\
20 \\
75^{*}\end{array}$ \\
\hline $\begin{array}{l}\text { LA, } \mathbf{N} \text { or }+ \\
\text { LA, }++ \\
\text { Total }\end{array}$ & $\begin{array}{c}7 \\
11 \\
23^{*}\end{array}$ & $\frac{1}{1}$ & $\frac{2}{2}$ & $\frac{3}{3}$ & $\frac{1}{1}$ & $\begin{array}{l}1 \\
2 \\
3\end{array}$ & $\begin{array}{l}3 \\
4 \\
7\end{array}$ & $\frac{12}{12}$ & $\begin{array}{r}18 \\
3 \\
21\end{array}$ & $\begin{array}{r}14 \\
4 \\
18\end{array}$ & $\begin{array}{r}8 \\
3 \\
11\end{array}$ & $\begin{array}{l}5 \\
1 \\
6\end{array}$ & $\frac{3}{3}$ & $\begin{array}{c}78 \\
28 \\
111^{*}\end{array}$ \\
\hline
\end{tabular}

Of the 52 electrocardiograms with sinus rhythm, P in V1 was diphasic in $36(72 \%)$. The double lines mark the limit of normal for each lead.

*All the 5 cases with the atrium greatly enlarged had auricular fibrillation so they have been added here.

The distribution of the height and breadth of the P waves in leads I and II, and the height of the $P$ wave in lead V1 are shown in Tables II and III. The cases were subdivided according to the appearance of the left atrium seen on screening, the size of the left atrium being denoted by a series of signs, + indicating slight, ++ moderate, +++ great, and ++++ aneurysmal enlargement of the atrium. It is realized that screening only gives a rough guide to the size of the various 
chambers of the heart but in this series all the assessments as to atrial size were made by one observer and are probably of value if only as an approximate index. Most of the cases show only slight or moderate enlargement of the left atrium, and this may well be a reflection of the type of case referred to Guy's at this time. The table shows that 23 cases have auricular fibrillation, and that the larger the atrium the more likely it is to be fibrillating.

Of the remaining fifty-two cases, twenty $(40 \%)$ show increase in height of $P$ in lead $I$, and eleven $(22 \%)$ in lead II. In lead VI a very high proportion ( $72 \%$ of those in sinus rhythm) show diphasic $P$ waves, as against 18 per cent given by Leatham as the normal value, and although the amplitude and duration of most of the $\mathbf{P}$ waves in this lead lay within the usual limits, there was a small group who were outside this range.

When the breadth of the $P$ waves is examined, twenty-four out of fifty-two (48\%) show a duration above the average limit of normal in lead II. It would, therefore, seem that both increase in amplitude and duration may occur in the $P$ waves in mitral stenosis, and that increased duration is slightly the commoner finding. Furthermore, diphasic P waves in lead Vl occur in a high proportion of cases.

TABLE III

Duration of P WaVes IN Lead II

\begin{tabular}{l|r|r|r|r|r|r|r|r}
\hline $\begin{array}{c}\text { Size of } \\
\text { Left Atr. }\end{array}$ & Aur. & \multicolumn{5}{|c}{ Duration of PII in seconds } \\
\cline { 2 - 6 } & Fib. & 0.16 & $0 \cdot 14$ & 0.12 & $0 \cdot 10$ & 0.08 & 0.06 & Total \\
\hline Normal & - & - & - & 1 & 1 & - & - & 2 \\
+ & 7 & 1 & 4 & 14 & 12 & 6 & 3 & 47 \\
++ & 11 & - & 1 & 3 & 3 & 2 & 1 & 21 \\
+++ or & & & & & & & & 5 \\
++++ & 5 & - & -5 & -18 & - & -5 & - & 75 \\
Total & 23 & 1 & 5 & 18 & 16 & 8 & 4 & 75 \\
\hline
\end{tabular}

The other frequently described change in the $\mathrm{P}$ waves is in its shape. Shape, unlike duration and amplitude, is not easily measured: it bears some relationship to duration and amplitude but this is by no means absolute. In this series the shape of the P wave was examined in lead I and II: the abnormal types described are the flat-topped $P$ wave and the pointed $P$ wave. Notching is described separately. Thirty-two cases (61\%) showed flat-topped P waves in either lead I or II. Pointed $P$ waves were much less common and were found on only six $(11 \%)$ occasions. Notching was found in sixteen cases $(31 \%)$ and was nearly always associated with the flat-topped type of $P$ wave.

When the amplitude and duration of the $\mathrm{P}$ waves are compared with the size of the left atrium, as shown by screening (Table II), there does not appear to be any relationship between them; although the small number of cases with large atria makes it difficult to form a definite opinion here.

Scatter charts were made to show the amplitude, breadth, and area of PI and PII plotted against the pulmonary artery pressure. It was thought that this pressure might bear some relationship to the degree of mitral stenosis, and therefore to the degree of resistance that the left atrium had to overcome, and that this resistance would lead to atrial hypertrophy and be mirrored in the $P$ waves. However, no relationship could be seen on the charts and it is probable that both the shape of the $P$ wave and the pulmonary artery pressure depend on many factors beside the size of the mitral aperture.

$P-R$ Interval. In 1916, White reported heart block occurring in rheumatic fever and since then, prolongation of the $\mathbf{P}-\mathbf{R}$ interval has been a classical, but by no means common, finding in this condition. In non-active rheumatic heart disease, however, changes in the $P-R$ interval seem rare. 
Rasmussen and Nyhus report it in only 4 out of 48 cases in their series. In only four cases $(8 \%)$ of this series was the upper limit of normal of $0.2 \mathrm{sec}$. exceeded, and it would therefore appear that prolongation of the $\mathbf{P}-\mathbf{R}$ interval rarely survives the acute phase of the rheumatic process.

Q-T Interval. Of recent years there has been considerable interest in the Q-T interval. In 1931, Berliner noted that it was prolonged in rheumatic heart disease, and this observation has been extended by Taran and Szilagyi (1947) in America, and by Abrahams (1949) in this country. They showed that increase in the Q-Tc (Q-T interval corrected for variation in heart rate) was a valuable indication of active carditis in rheumatic fever.

The Q-T interval was measured in this series of cases and compared with the standard values given by Ashman and Hull (1941). In all cases it was within normal limits.

Axis Deviation and Position of the Heart. The exact electrical axis of the heart has not been calculated, as this aspect has already been fully described by Rasmussen and Nyhus (1948). The cases were diagnosed as right axis deviation if both the following criteria were fulfilled: (i) in lead I, $\mathbf{S}>$ twice $\mathbf{R}$, and (ii) in lead III $\mathbf{R}>$ twice $S$. Left axis deviation was diagnosed when the converse was found. It is probable that the electrical axis of the heart depends as much on its position as on the relative size of the two ventricles, though of course these two factors cannot be entirely separated.

With the introduction of unipolar chest and limb leads it has become possible to obtain a more accurate picture of the position of the heart. When the heart is vertical the chest leads from the left ventricle are reflected in $\mathrm{VF}$, and $\mathrm{VL}$ is predominantly negative.

Out of the seventy-five cases in this series, twenty-two $(29 \%)$ showed right axis deviation, fiftytwo $(70 \%)$ no axis deviation, and one $(1 \%)$ left axis deviation. This is rather a lower incidence of right axis deviation than the 43 per cent reported by White and Burwell (1924) and approximates to the 26 per cent found by Rasmussen and Nyhus (1948). A high proportion of all cases $(68 \%)$ had a vertical heart and in every case with right axis deviation the heart was in this position.

The other noticeable feature in the ventricular complex was the frequent appearance $(68 \%)$ of an $r R R$ pattern in the standard leads with a small $r$ wave in lead $I$ and normal or large $R$ waves in leads II and III (Fig. 1). This occurred in every case with right axis deviation and in a further twenty-nine with no axis deviation.

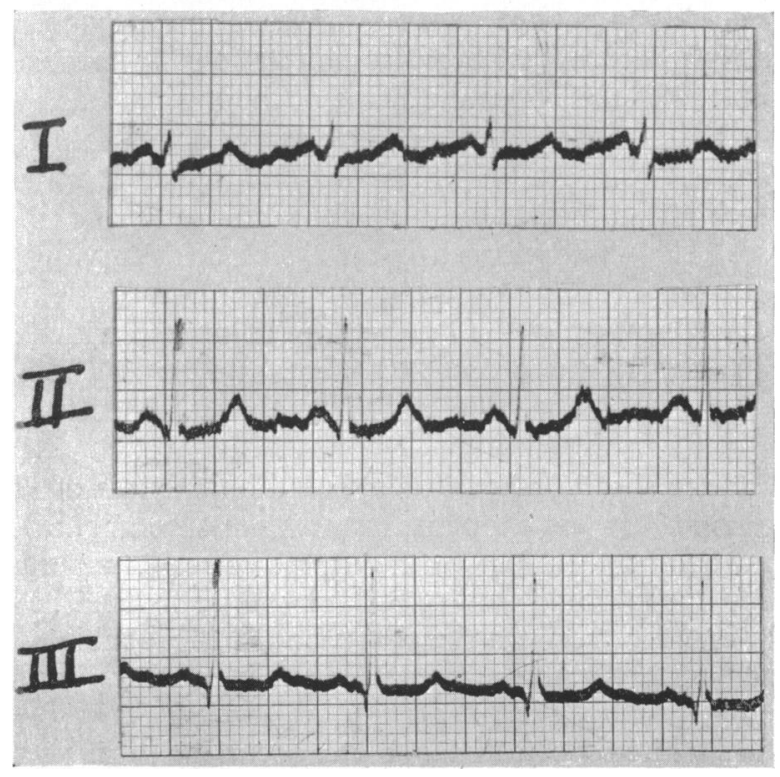

Fig. 1 
In the thirty-five patients who had been catheterized so that the diagnosis of atrial septal defect could be excluded, only two showed an $R^{1}{ }^{1}$ pattern in lead V1 and this was never found in V2. This would serve as a further useful point in differentiating mitral stenosis from atrial septal defect.

Ventricular Hypertrophy. The introduction of unipolar chest leads has enabled a more accurate assessment of the relative thickness of the ventricles, although the cardiographic signs of right ventricular hypertrophy are not so clear-cut as those of left. In this series the criteria laid down by Sokolow and Lyon (1949) have been used. They may be summarized as follows.

(1) Large $\mathrm{R}$ wave and small $\mathrm{S}$ wave in the right præcordial leads especially lead V1.

(2) Delayed onset of the intrinsicoid deflection in lead V1.

(3) Small $R$ waves and large S waves in lead V5 and V6.

(4) S-T depression and T inversion in leads V1 and V2 and also in leads VL or VF and in leads II and III. This last group of changes are inconstant.

Thirty-five (47\%) of the seventy-five cases showed electrocardiographic evidence of right ventricular hypertrophy. An analysis of the occurrence of the various criteria is given in Table IV and it will be seen that an $\mathrm{R} / \mathrm{S}$ ratio of greater than one is the most frequent sign. Recently a prominent late $R$ wave in lead aVR has been described in cases of right ventricular hypertrophy due to lung disease (Kilpatrick, 1951). This change was only found in five cases of this series, all of which showed other cardiographic evidence of right ventricular hypertrophy. Only one record showed evidence of left ventricular hypertrophy: although there was no clinical evidence of aortic valve disease, screening was a little suggestive of aortic regurgitation and this offers the most likely explanation. If right ventricular hypertrophy was found on the electrocardiogram it was confirmed on fluoroscopy in 91 per cent of the cases. However, in a further thirty-four cases there was right ventricular enlargement on screening that was not demonstrated by the cardiogram. This suggests that screening is the more sensitive method of detecting this change, but the enlarged right ventricular outline seen on X-ray may, in some cases, be due to dilatation rather than hypertrophy and may, therefore, not show on the cardiogram.

TABLE IV

ANalysis of Criteria on Which Diagnosis of Right Ventricular HYPERTROPHY WAS MADE

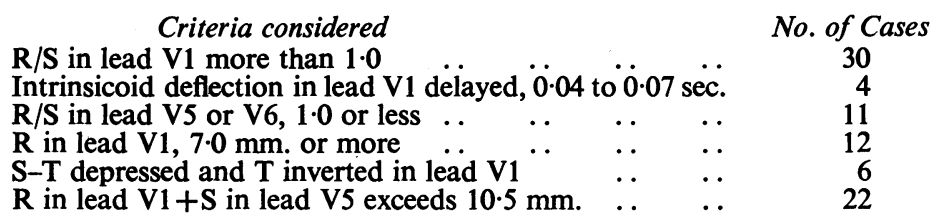

It seemed possible that there would be some relationship between pulmonary artery pressure and right ventricular hypertrophy, although of course other factors, such as the duration of this raised pressure, probably play a part. Table $\mathrm{V}$ shows that a high pulmonary artery pressure is usually, but by no means always, associated with electrocardiographic evidence of right ventricular hypertrophy. On the other hand, in some cases with an apparently normal pulmonary artery pressure there was evidence of right ventricular hypertrophy. A possible reason for this is that the pulmonary artery pressure in these cases rises very steeply on exercise and thus the right ventricle has more work to do than is suggested by the resting pressure (Baylis et al., 1950). This was confirmed in two cases who had their pulmonary artery pressure measured before and after exercise, the pressures rising from 27 to $100 \mathrm{~mm}$., and from 28 to $65 \mathrm{~mm}$. $\mathrm{Hg}$ respectively.

As an extension of these observations the pulmonary artery pressure was compared with the degree of the various cardiographic changes found in right ventricular hypertrophy to decide whether any relationship could be demonstrated. When these electrocardiographic changes are 
TABLE V

Relation Between Pulmonary Artery Pressure and Electrocardiographic

EVIDENCE OF R.V. HYPERTROPHY

$\begin{array}{ccccr}\text { Cases with raised pulmonary artery pressure } & & & \\ \text { i.e. mean, above } 30 \mathrm{~mm} \text {. Hg } & \ldots & . . & \ldots & 24 \\ \text { with R.V. hypertrophy electrocardiographically } & . & \ldots & 15 \\ \text { with no hypertrophy electrocardiographically } & . & \ldots & 9 \\ \text { Cases with normal pulmonary artery pressure } & \ldots & \ldots & 11 \\ \text { with R.V. hypertrophy electrocardiographically } & \ldots & \ldots & 4 \\ \text { with no hypertrophy electrocardiographically } & \ldots & \ldots & 7\end{array}$

taken individually, it is difficult to decide whether they are in fact an index of ventricular hypertrophy. Recent work by McGregor (1950) has emphasized the part played by rotation in the genesis of the right ventricular hypertrophy pattern, and many of the changes would appear to be caused by rotation, and only indirectly by increased ventricular bulk. Nevertheless, the theoretical bases of the electrocardiography is still far from settled, and it was therefore decided to test for correlation without being too concerned with the exact method of production of these changes. The following criteria were compared with the pulmonary artery pressure: (1) amplitude of R in V1, (2) amplitude of $\mathrm{S}$ in V5, (3) R/S in V1, (4) R/S in V5, (5) S in V1+R in V5, and (6) R in V1+S in V5. The only noticeable degree of correlation occurs when $S$ in V1 $+R$ in V5 is compared with the pulmonary artery pressure as is shown in the scatter chart (Fig. 2). This is surprising as this particular combination is not usually taken as a criteriort of right ventricular hypertrophy. It will be seen, however, that in the group mentioned the correlation is by no means close, and it is obvious

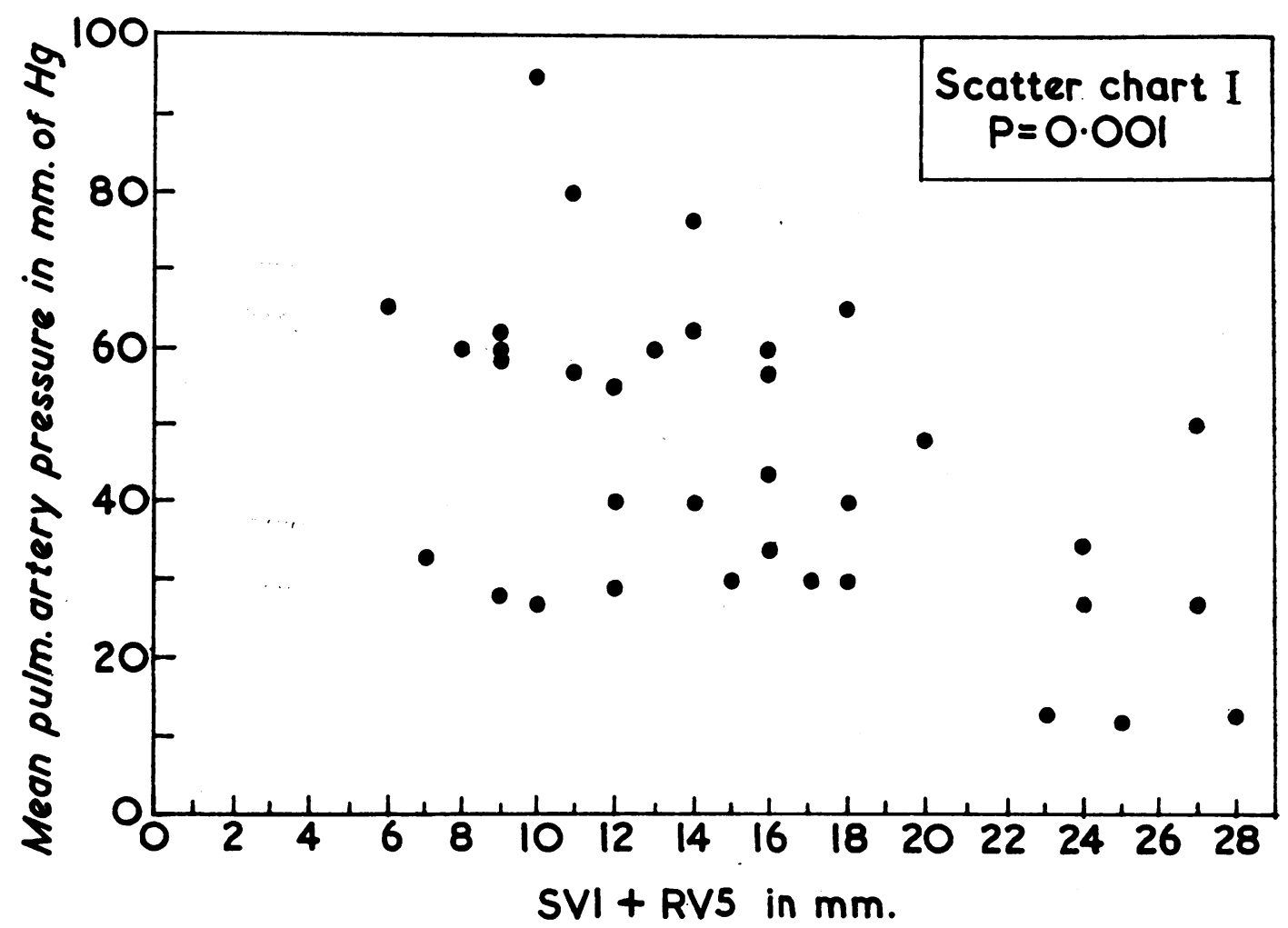

Fig. 2 
that the cardiographic pattern offers no short cut to the assessment of the degree of pulmonary artery pressure.

\section{Discussion}

There were two main objectives in this paper: the first to describe how often various changes occur in cases of mitral stenosis, and the second to relate these changes to the abnormal anatomy and physiology of the heart, as shown by fluoroscopy and cardiac catheterization.

The first of these objectives is largely a repitition of work already done, and in the main confirms previous findings. The chief changes in the standard leads are confined to $P$ wave abnormalities, and to right axis deviation. The use of unipolar leads has stressed how frequently the heart is vertical and how often it shows evidence of right ventricular hypertrophy. The presence of diphasic $P$ waves in lead V1 is a frequent finding of interest, and may be of some diagnostic value. In the main, however, there is little to add to Sir Thomas Lewis's description of some forty years ago.

It was not possible to show any close relationship between the electrocardiogram and other changes in the heart. The $P$ wave changes seem to bear little relation to the size of the left atrium or to the pulmonary artery pressure. Similarly, although some correlation could be traced between cardiographic signs of right ventricular hypertrophy and pulmonary artery pressure, the relationship seems very variable and of little practical use.

With a further understanding of the physical bases of the electrocardiogram, it may be possible to interpret wave changes more exactly in terms of altered cardiac anatomy and physiology, and finally, perhaps to give these changes a quantitative, as well as qualitative value. Meanwhile, although it is possible to discern certain vague quantitative relationships our knowledge remains limited to the presence, rather than to the degree of change.

\section{SUMMARY}

The electrocardiographic changes in seventy-five cases of mitral stenosis are described.

The most frequent changes are found in the $P$ waves, in a tendency to right axis deviation and right ventricular hypertrophy, and in the presence of an $\mathrm{RRR}$ pattern in the standard leads.

Biphasic $P$ waves in lead V1 are a common finding and may be of some diagnostic use.

No clear relationship could be shown between the size of the left atrium and the amplitude or duration of the $P$ wave.

Some relationship could be shown between the pulmonary artery pressure and right ventricular hypertrophy as shown by the unipolar chest leads.

The author wishes to thank Dr. Maurice Campbell and Dr. Charles Baker for their help and encouragement in preparing this paper.

\section{REFERENCES}

Abrahams, D. G. (1949). Brit. Heart J., 11, 342.

Alexander, A. A., Knight, H. F., and White, P. D. (1925). Arch. intern. Med., 36, 712.

Ashman, R., and Hull, E. (1941). Essentials of Electrocardiography. 2nd ed. The MacMillan Company, New York.

Bain, C. W. C., and Redfern, E. McV. (1948). Brit. Heart J., 10, 9.

Baker, C. G., Brock, R. C., and Campbell, M. (1950). Brit. med. J., 1, 1283.

Baylis, R. I. S., Ethridge, M. J., and Hyman, A. L. (1950). Lancet, 2, 889.

Barber, J. M., Magidson, O., and Wood, P. (1950). Brit. Heart J., 12, 277.

Berliner, K. (1931). Amer. Heart J., 7, 189.

- and Masters, A. M. (1938). Arch. intern. Med., 61, 39.

Evans, W. (1948). Cardiography. Butterworth \& Co. Ltd., London.

Johnson, J. B., Ferrer, M. I., West, J. R., and Cournand, A. (1950). Circulation, 1, 536.

Kilpatrick, J. A. (1951). Brit. Heart, J, 13, 309. 
Leatham, A. (1950). Brit. Heart J., 12, 213.

Lewis, T. (1913). Clinical Electrocardiography. Shaw \& Sons, London.

McGregor, M. (1950). Brit. Heart J., 12, 351.

Myers, G. B., Klein, H. A., and Stofer, B. E. (1948). Amer. Heart J., 35, 1.

Pardee, H. (1917). J. Amer. med. Ass., 68, 1250.

Rasmussen, H., and Nyhus, G. (1948). Acta med. Scand., 129, 446.

Sokolow, M., and Lyon, T. P. (1949). Amer. Heart J., 37, 161, and 38, 273.

Taran, L. M., and Szilagyi, N. (1947). Amer. Heart. J., 33, 14.

White, B. V., Parker, R. C., and Masters, A. M. (1944). Arch. intern. Med., 74, 94.

White, P. D. (1916). Amer. J. med. Sci., 152, 589.

$\longrightarrow$, and Burwell, C. S. (1924). Arch intern. Med., 34, 529. 